\title{
Ghrelin inhibits leptin- and activation-induced proinflammatory cytokine expression by human monocytes and T cells
}

\author{
Vishwa Deep Dixit, ${ }^{1}$ Eric M. Schaffer, ${ }^{1}$ Robert S. Pyle, ${ }^{1}$ Gary D. Collins, ${ }^{1}$ Senthil K. Sakthivel, ${ }^{2}$ \\ Ravichandran Palaniappan, ${ }^{2}$ James W. Lillard Jr., ${ }^{2}$ and Dennis D. Taub ${ }^{1}$ \\ ${ }^{1}$ Laboratory of Immunology, National Institute on Aging, NIH, Baltimore, Maryland, USA. ${ }^{2}$ Department of Microbiology and Immunology, \\ Morehouse School of Medicine, Atlanta, Georgia, USA.
}

\begin{abstract}
Ghrelin, a recently described endogenous ligand for the growth hormone secretagogue receptor (GHS-R), is produced by stomach cells and is a potent circulating orexigen, controlling energy expenditure, adiposity, and growth hormone secretion. However, the functional role of ghrelin in regulation of immune responses remains undefined. Here we report that GHS-R and ghrelin are expressed in human T lymphocytes and monocytes, where ghrelin acts via GHS-R to specifically inhibit the expression of proinflammatory anorectic cytokines such as IL-1 $\beta$, IL-6, and TNF- $\alpha$. Ghrelin led to a dose-dependent inhibition of leptin-induced cytokine expression, while leptin upregulated GHS-R expression on human $T$ lymphocytes. These data suggest the existence of a reciprocal regulatory network by which ghrelin and leptin control immune cell activation and inflammation. Moreover, ghrelin also exerts potent anti-inflammatory effects and attenuates endotoxin-induced anorexia in a murine endotoxemia model. We believe this to be the first report demonstrating that ghrelin functions as a key signal, coupling the metabolic axis to the immune system, and supporting the potential use of ghrelin and GHS-R agonists in the management of disease-associated cachexia.
\end{abstract}

\section{Introduction}

Ghrelin is a 28-amino-acid acylated polypeptide secreted predominantly from $\mathrm{X} / \mathrm{A}$-like enteroendocrine cells of the stomach $(1,2)$. Several lines of evidence implicate ghrelin in growth hormone (GH) release, energy balance, food intake, and long-term regulation of body weight in rodents $(3,4)$ and humans $(5)$. The ghrelin gene encodes a 117-amino-acid peptide, preproghrelin, for which there is an $82 \%$ homology between rat and human (1). Ghrelin is presently regarded as the only known circulating orexigen and exerts antagonistic effects on the leptin-induced decrease in food intake through activation of the hypothalamic neuropeptide Y-Y1 (NPY-Y1) pathway $(3,6)$. The effects of ghrelin are mediated via a 7-transmembrane $\mathrm{G}$ protein-coupled receptor (GPCR) called growth hormone secretagogue receptor (GHS-R) (7). This receptor is evolutionarily conserved from puffer fish to humans (8), which suggests that ghrelin may play a fundamental role in organism growth and development. The GHS-R type 1a has been implicated in GH release, and a nonspliced, nonfunctional receptor mRNA variant identified as GHS-R type $1 \mathrm{~b}$ has recently been identified within a wide variety of tissues including lymphoid organs (9). Hexarelin is a synthetic analogue that binds GHS-R to induce GH secretion from porcine and bovine PBMCs, which suggests that GHS-R ligands may exert some direct effects on the immune system (10). In addition, the wide tissue distribution of GHS-R in the lymphoid system suggests that ghrelin and GHS-R ligands may function as signal modulators among the endocrine, nervous, and immune systems.

Nonstandard abbreviations used: Alexa Fluor (AF); G protein-coupled receptor (GPCR); growth hormone (GH); growth hormone secretagogue receptor (GHS-R); neuropeptide Y (NPY); stromal cell-derived factor-1 $\alpha$ (SDF-1 $\alpha$ ); T cell receptor (TCR). Conflict of interest: The authors have declared that no conflict of interest exists.

Citation for this article: J. Clin. Invest. 114:57-66 (2004).

doi:10.1172/JCI200421134
Inflammatory cytokines released by immune cells have been shown to act on the CNS to control food intake and energy homeostasis (11). Decrease in food intake and anorexia are among the most common symptoms of illness, injury, or inflammation (12). Cytokines such as IL-1 $\beta$, IL- 6 , and TNF- $\alpha$ have been implicated in wasting associated with inflammation (13), chronic low-grade inflammation in aging $(14,15)$, and atherosclerosis (16). Regulation of inflammatory cytokine production by endogenous factors holds promise in the amelioration of a wide variety of ailments and disease conditions. In the present report, we describe a novel function of ghrelin in the immune system and on proinflammatory cytokine expression by human $\mathrm{T}$ cells and mononuclear cells upon cellular activation or leptin exposure. These results have implications in the potential use of ghrelin as a therapeutic target associated with a host of inflammatory diseases.

\section{Results}

GHS-R is a functional receptor expressed on the surface of human $T$ cells. While previous results have described only the mRNA expression of GHS-R in lymphoid organs (9), our initial studies focused on the expression and spatial localization of GHS-R protein in purified human T cells. GHS-R displayed a heterogeneous subcellular expression pattern in resting human $T$ cells, ranging from crescent to punctate or diffuse phenotypes (Figure 1A, upper panel, and Supplemental Figure 1B; supplemental material available at http:// www.jci.org/cgi/content/full/114/1/57/DC1). In resting T cells, the majority of ghrelin receptors were segregated from the $\mathrm{GM} 1^{+}$ lipid rafts (Figure 1A, upper panel). However, upon activation of $\mathrm{T}$ cells via $\mathrm{T}$ cell receptor (TCR) ligation, we observed a dramatic subcellular reorganization of GHS-R, demonstrating a polarized capped phenotype and aggregation in lipid rafts (Figure 1A, lower panel). Flow cytometric analysis revealed that up to $30 \%$ of highly purified resting human $\mathrm{T}$ cells exhibited specific staining for 
GHS-R as demonstrated via the use of a blocking peptide (Figure $1 B)$. In contrast, in human PBMCs, no preferential expression pattern of GHS-R was observed on $\mathrm{CD}^{+}, \mathrm{CD}^{+}{ }^{+} \mathrm{CD} 4^{+}$, and $\mathrm{CD}^{+} \mathrm{CD}^{+}$ $\mathrm{T}$ cells (data not shown). In highly purified human $\mathrm{T}$ cells, GHS-R expression significantly increased upon cellular activation (Figure 1C), and in the presence of antibody-specific blocking peptide, this GHS-R labeling was almost completely ablated. Moreover, upon $\mathrm{T}$ cell activation, there was also a marked upregulation of GHS-R gene expression, as demonstrated by quantitative analysis of PCR products using Agilent gene chip technology (Agilent Technologies, Palo Alto, California, USA) and real time RT-PCR (Figure 1D). GHS-R mRNA was found to be upregulated in T cells as early as 6-12 hours after activation, with colocalization in $\mathrm{GM} 1^{+}$domains.

The presence of GHS-R within lipid rafts and specific upregulation of the GHS-R gene upon T cell activation strongly supports a role for these receptors in $\mathrm{T}$ cell function. We observed a similar staining pattern for ghrelin receptors on activated $\mathrm{T}$ cells utilizing a second antibody recognizing amino acid residues $186-265$ proximal to the C terminal region of human GHS-R (Supplemental Figure 1A).

Ligation of seven transmembrane GPCRs typically results in calcium mobilization from the intracellular stores by generation of inositol triphosphate $(1,17)$. Ghrelin has previously been shown to induce intracellular calcium release in GHS-R-transfected CHO cells (1). Here, using cultured human T cells, we demonstrate a significant and specific rise in intracellular $\left[\mathrm{Ca}^{2+}\right]$ in response to both full-length ghrelin peptide (Figure 1E) as well as ghrelin 1-18 fragment, while the des-acyl ghrelin did not elicit calcium release (data not shown). This ghrelin-induced calcium flux was found to be GHS-R specific, as pretreatment with [D-Lys-3]-GHRP-6, a highly selective GHS-R antagonist, markedly attenuated the ghrelin-mediated intracellular calcium release from $\mathrm{T}$ cells (Figure 1E). Interestingly, the intracellular calcium mobilization induced by ghrelin treatment was similar in magnitude to that observed in response to our positive control, stromal cell-derived factor-1 $\alpha$ (SDF-1 $\alpha$ ), a potent $\mathrm{T}$ cell chemokine ligand that specifically binds and signals through the cell surface GPCR, CXCR4 (18). In addition to calcium mobilization, ligation of GPCRs is often accompanied by a dramatic remodeling of the actin cytoskeleton and cell surface molecules and leads to polarization and, in many cases, the directional migration of immune cells $(19,20)$. Here, ghrelin induced a marked increase in broad membrane structures characteristic of lamellipodia with typical polarization of F-actin in a manner quite similar to the SDF-1 $\alpha$-treated cells (Figure 1F). Together, these data demonstrate the presence of functional GHS-R on the surface of human

\section{Figure 1}

Expression of functional GHS-R in human $T$ cells. (A) Primary human $T$ cells were labeled for GHS-R, and subcellular localization in lipid rafts was visualized in resting and anti-CD3-activated cells. Arrowheads indicate colocalization of GHS-R with polarized lipid rafts. (B) Flow cytometric analysis of GHS-R on highly purified resting human $T$ cells. Specific $\mathrm{T}$ cell labeling (green) was abolished in presence of antibody-specific blocking peptide (blue). T cells stained with control IgG demonstrated no specific labeling. (C) Flow analysis of GHS-R expression on highly purified (>96\%) activated $\mathrm{CD}^{+}$human T cells. Staining specificity was demonstrated through the use of antibody-specific blocking peptide. (D) GHS-R mRNA is upregulated upon T cell activation as assessed using Agilent gene chip quantitation and real time RT-PCR; values are expressed as mean \pm SEM $\left({ }^{*} P<0.05\right)$. (E) Ghrelin induces intracellular calcium mobilization in cultured human $T$ cells. $T$ cells were stimulated with ghrelin (100 $\mathrm{ng} / \mathrm{ml}$; blue), or SDF-1 (100 $\mathrm{ng} / \mathrm{ml}$; green) at 60 seconds. T cells were also treated with the GHS-R antagonist, [D-Lys-3]-GHRP-6 (10-4 M), at 60 seconds followed by ghrelin $(100 \mathrm{ng} / \mathrm{ml}$; red) at 180 seconds. FL, fluorescence. (F) Ghrelin causes actin-polymerization in human T cells. Cells were treated with ghrelin $(100 \mathrm{ng} / \mathrm{ml})$ and positive control SDF-1 $\alpha(100 \mathrm{ng} / \mathrm{ml})$ for 20 minutes and labeled for F-actin with phalloidin AF-594. Arrowheads indicate polymerized F-actin associated with lamellipodia of cells.
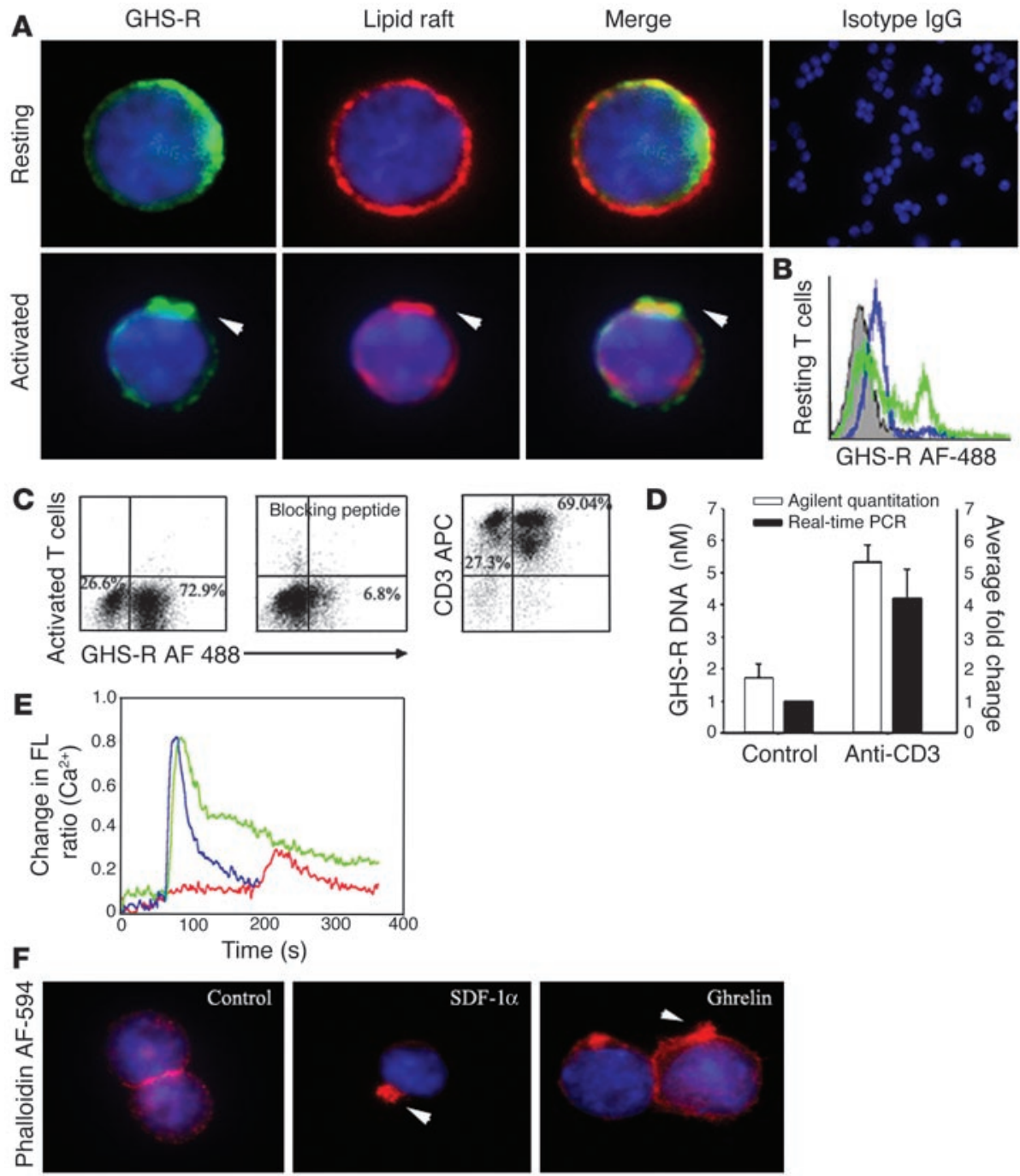
A

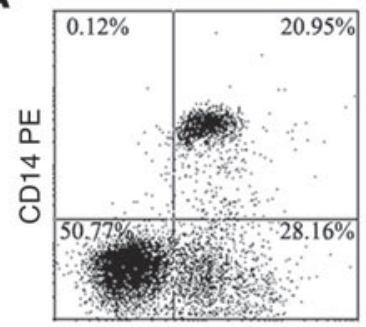

GHS-R AF-488
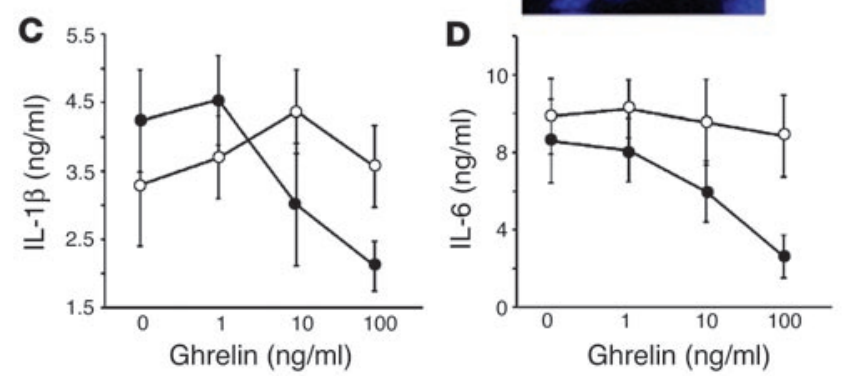

Figure 2

Ghrelin receptors are expressed on human monocytes. (A) Human PBMCs were double stained with CD14 PE and GHS-R AF-488. (B) Immunofluorescence labeling revealed GHS-R expression on cell surface of purified monocytes (upper panel); negative control failed to show any specific staining (lower panel). Ghrelin inhibits IL-1 $\beta$ (C) and IL-6 (D) secretion from LPS-treated $(10 \mathrm{ng} / \mathrm{ml})$ monocytes.

T cells and mononuclear cell subsets and support a biological role for ghrelin and GHS-R within the immune system.

GHS-R is expressed in human monocytes, and ghrelin inhibits inflammatory cytokines. Among the mononuclear cells, monocytes constitute an important source of proinflammatory cytokines, which prompted us to examine the GHS-R expression on monocytes. Flow cytometric analysis revealed that approximately $21 \%$ of CD $14^{+}$ cells expressed GHS-R (Figure 2A). Using immunofluorescence microscopy, we detected diffuse GHS-R expression on the cell surface of purified monocytes (Figure 2B, upper panel), and control IgG demonstrated no specific labeling (Figure 2B, lower panel). Similarly, GHS-R expression was observed in immature and mature monocyte-derived dendritic cells (data not shown). Real time RT-PCR analysis also demonstrated the presence of GHS-R type 1a mRNA in monocytes with similar expression levels to primary human $\mathrm{T}$ cells (data not shown). Furthermore, ghrelin led to a dose-dependent inhibition of IL-1 $\beta$ and IL-6 (Figure 2, C and D) via a GHS-R-specific pathway, as concomitant treatment with GHS-R antagonist blunted these effects.

Ghrelin selectively inhibits proinflammatory cytokine expression. The classical proinflammatory cytokines, IL-1 $\alpha$, IL-1 $\beta$, IL-6, and TNF- $\alpha$, are known to play a critical role in development of anorexia-cachexia syndrome (21). Anorexia-cachexia syndrome is a complex multifactorial metabolic condition associated with altered protein, carbohydrate, and fat metabolism resulting in anorexia, negative energy balance, weight loss, and muscle wasting (13). It has been hypothesized that ghrelin is involved in mealtime hunger and long-term regulation of body weight $(4,5)$. Considering the critical role played by proinflammatory cytokines in controlling metabolic activity, we next examined the ability of ghrelin to regu- late the production of IL-1 $\beta$, IL- 6 , and TNF- $\alpha$ by activated PBMCs and $\mathrm{T}$ cells. Human PBMCs derived from healthy male subjects were stimulated with the polyclonal mitogen phytohemagglutinin and incubated in the presence or absence of ghrelin and GHS-R antagonist for 24 hours, after which supernatants were collected and examined for cytokine levels. Interestingly, ghrelin treatment resulted in a significant inhibition of IL- $1 \beta$, IL- 6 , and TNF- $\alpha$ production by PBMCs at ghrelin levels ranging from 1 to $100 \mathrm{ng} / \mathrm{ml}$ (Figure 3, A-C); however, ghrelin treatment failed to alter TGF- $\beta$ production by these PBMCs at any concentration tested (Figure 3D). This effect was found to be GHS-R specific, as the addition of GHS-R antagonist to these cultures attenuated this ghrelin-mediated inhibition, and similar ghrelin effects on cytokine production were observed using concanavalin A-stimulated PBMCs (data not shown) and LPS-treated monocytes. In addition, the primary human $\mathrm{T}$ cells stimulated with immobilized anti-CD3 antibody in the presence of ghrelin for 24 hours demonstrated a significant dose-dependent inhibition of IL-1 $\beta$ and IL-6 (Figure 3, E-G). TNF- $\alpha$ secretion by $T$ cells also demonstrated a reproducible declining trend in response to ghrelin, as was observed in the PBMC studies; however, due to individual variations in TNF- $\alpha$ production among these donors, this inhibition failed to reach statistical significance $(P>0.05)$. It should also be noted that this ghrelin-mediated inhibition was not due to any cytolytic effects of the hormone on T cells or PBMCs, as measurement of lactate dehydrogenase and cell counts using trypan blue exclusion failed to demonstrate any significant difference between control and hormone-treated cells. Furthermore, ghrelin had no significant effect on proliferation or IL-2 (Supplemental Figure 1C) and IFN- $\gamma$ secretion (data not shown) from human $\mathrm{T}$ cells. Using realtime RT-PCR analysis, we further demonstrate that ghrelin significantly inhibits IL-1 $\beta$. A ghrelin dose of $10-100 \mathrm{ng} / \mathrm{ml}$ inhibited IL- 6 and TNF- $\alpha$ mRNA expression in all the donors, demonstrating a reduction in cytokine production (Figure $3 \mathrm{H}$ ). These results strongly support a role for ghrelin in the transcriptional regulation of inflammatory cytokine expression.

Ghrelin inhibits leptin-mediated proinflammatory cytokine expression. As leptin and ghrelin exert antagonistic effects on food intake at the hypothalamic level $(4,6)$, we next sought to determine the mechanism by which these metabolic hormones regulate inflammatory cytokine production. Recent studies have demonstrated that leptin-deficient mice are protected from $\mathrm{T}$ cell-mediated hepatotoxicity (22) and that leptin exerts proinflammatory effects in these mice (23). In humans, leptin has been recently shown to increase IL- 6 and TNF- $\alpha$ protein production by PBMCs and monocytes (24). Human T cells and porcine PBMCs have also been shown to express leptin receptor (Ob-R) mRNA $(25,26)$. In support of these findings, we demonstrate here the diffuse expression of Ob-R protein on the surface of human T cells (Figure 4A). Moreover, we have shown, we believe for the first time, that leptin directly induces a significant dose-dependent increase in IL-1 $\beta$ (Figure 4B), IL-6 (Figure 4C), and TNF- $\alpha$ (Figure 4D) protein and mRNA expression by primary human T cells (Figure 4E) and PBMCs (data not shown). Upon concomitant addition of ghrelin to these cultures, a dose-dependent inhibition of leptin-induced cytokine protein and gene expression by $\mathrm{T}$ cells was observed in response to various concentrations of ghrelin (Figure 4, B-E). This strongly suggests that ghrelin and leptin, similar to their mutually antagonistic effects on food intake in hypothalamus, also exert reciprocal regulatory effects on inflammatory cytokine expression 

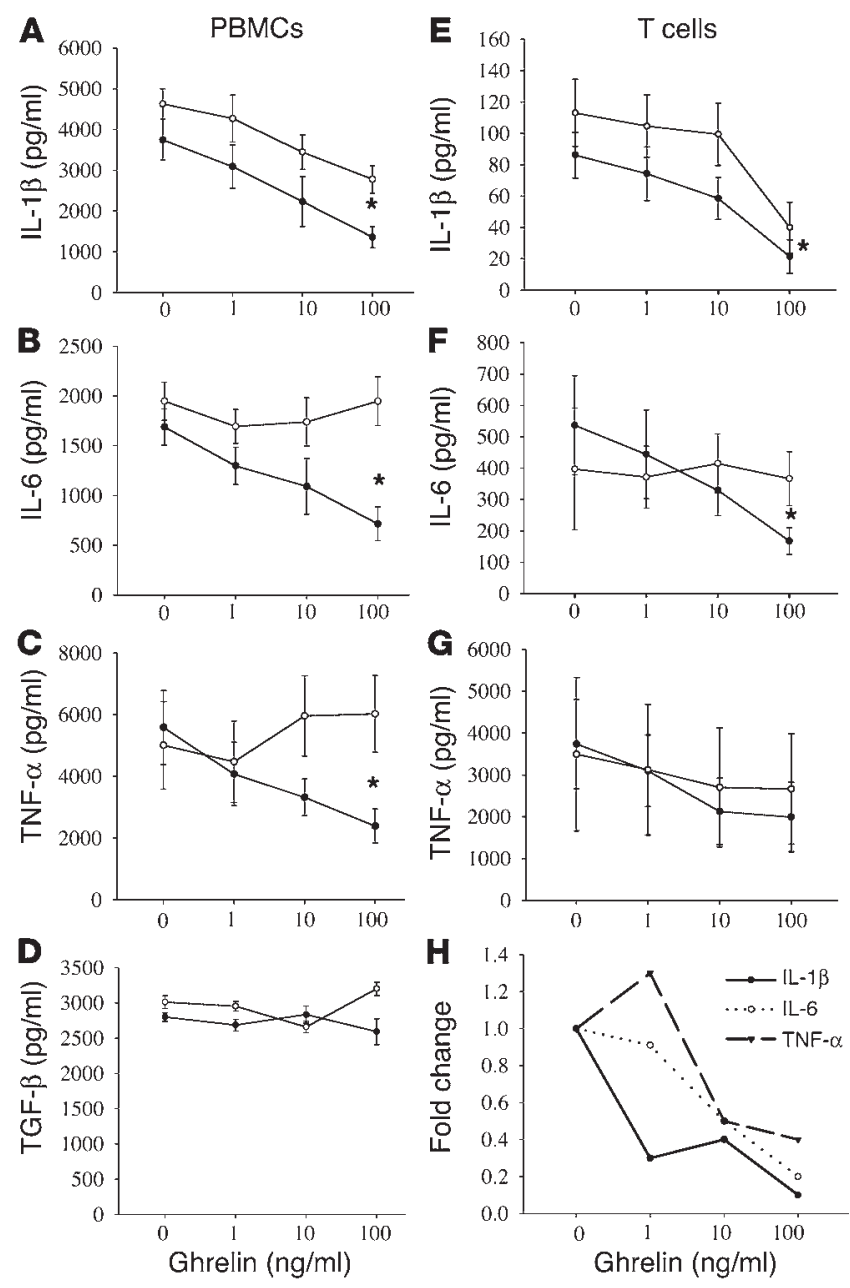

in the immune system. Thus, the variations in circulating levels of leptin and ghrelin may significantly influence the production of various cytokines by immune cell populations. Such reciprocal immunoregulatory effects may be critical in maintaining immune cell homeostasis, thereby preventing aberrant cytokine production, which may result in or amplify illness and pathology.

Human T cells express and actively secrete ghrelin. Ghrelin is currently thought to be produced exclusively by the stomach and subsequently secreted into the peripheral circulation (1). However, recent reports have demonstrated that peripheral ghrelin levels gradually increase after gastrectomy, suggesting that additional cellular sources of ghrelin compensate for stomach-derived ghrelin (27). Lymphocytes are known to produce many well-characterized hormones, such as GH (26), which exerts a number of regulatory effects on the immune system (28). Given the potent effect of ghrelin on cytokine expression, the possible presence of ghrelin endogenously produced by immune cells was hypothesized. Our results demonstrate the presence of immunoreactive ghrelin and GHS-R (Figure 5A, upper panel) in resting human T cells with a broad distribution phenotype, with areas of colocalization suggesting possible ligand-receptor interaction and an autocrine role for ghrelin in T cells. Interestingly, upon TCR ligation, a distinct change in the spatial localization of the endogenous immunoreactive ghrelin was observed, resulting in a polarized expression phenotype. Ghrelin appeared to specifically associate within GM1+ lipid rafts

\section{Figure 3}

Ghrelin inhibits inflammatory cytokine expression from human PBMCs and T cells. Human PBMCs $(n=6)$ were stimulated with phytohemagglutinin (PHA) $(1 \mu \mathrm{g} / \mathrm{ml})(\mathbf{A}-\mathbf{D})$, or T cells were activated via immobilized anti-CD3 antibody $(\mathbf{E}-\mathbf{H})$ in presence or absence of various doses of ghrelin (closed circles) and concomitantly with GHS-R antagonist, [D-Lys-3]-GHRP-6 (10-4 M; open circles) for 24 hours. The harvested supernatants were subsequently assayed for IL-1 $\beta$ (A and E), IL-6 (B and F), and TNF- $\alpha$ (C and G) and TGF- $\beta$ (D). The cytokine protein data is expressed as the mean \pm SEM representing six healthy adult donors $\left({ }^{\star} P<0.05\right)$. (H) Fold change in IL-1 $\beta$, IL-6, and TNF- $\alpha$ mRNA expression in T cells after normalization with GAPDH, measured by real time RT-PCR.

(Figure 5A, middle panel), suggesting that, upon activation, ghrelin may be produced and specifically targeted toward lipid rafts and its own specific receptor. In further support of ghrelin synthesis by human $\mathrm{T}$ cells, we found that the 117 -amino-acid prepro form of ghrelin is also coexpressed and colocalized within the Golgi apparatus (Figure 5A, lower panel), where the preproghrelin is presumably cleaved and processed to its mature form prior to secretion. Both ghrelin and preproghrelin staining in primary $\mathrm{T}$ cells was abolished upon addition of antibody-specific blocking peptide (Supplemental Figure 1D).

These findings are further supported by flow cytometric analysis of various $T$ cell subsets for the mature ghrelin protein: the majority of $\mathrm{T}$ cells appeared to be ghrelin positive with no preferential expression in $\mathrm{CD}^{+} \mathrm{CD}^{+}$or $\mathrm{CD}^{+}{ }^{+} \mathrm{CD} 8^{+} \mathrm{T}$ cell subsets. In addition to expression of intracellular ghrelin by T cells, TCR ligation of these cells resulted in the secretion of substantial levels of ghrelin protein into the culture supernatant, with levels peaking at 48 hours and declining thereafter (Figure 5B). Furthermore, $\mathrm{T}$ cell activation induced a greater than fivefold increase in ghrelin mRNA expression, as demonstrated by real time RT-PCR analysis (Figure 5C). We also demonstrate that acylated (active) ghrelin is coexpressed in human PBMCs with total ghrelin in 30\% of cells (Supplemental Figure 2).

Given the presence and production of ghrelin by $\mathrm{T}$ cells, it is possible that ghrelin concentrations within the local microenvironment may reach significantly high levels without undergoing the classic dilution effect typically seen upon the release of ghrelin from stomach into the peripheral circulation. Thus, $\mathrm{T}$ cell-derived ghrelin may serve an important role in regulating cell function within an immune microenvironment or organ. Considering the specific antagonistic effect of ghrelin on leptin-mediated inflammatory cytokine expression and the previous studies demonstrating leptin-induced ghrelin inhibition in the stomach (29), we next examined the possible cross-regulatory effects of leptin on ghrelin and GHS-R expression in T cells. In our current studies, leptin failed to exert any significant effects on ghrelin protein production or gene expression within human $\mathrm{T}$ cell cultures (Figure 5D). More interestingly, we noted that leptin treatment resulted in a significant increase in GHS-R mRNA expression by human $\mathrm{T}$ cells as measured by real-time RT-PCR (Figure 5E). Hence, the downregulation of leptin-induced cytokine expression by ghrelin may constitute a reciprocal regulatory signaling pathway by which these hormones control each other's activities within the immune system (Figure 5F). In addition, real-time PCR analysis revealed that ghrelin expression levels in human stomach were 11-fold higher than in lymphoid organs (T cells, spleen, and thymus) (Fig- 


\section{A}

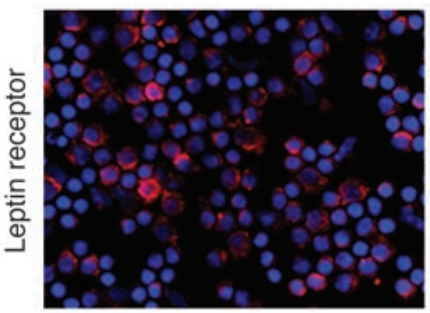

B

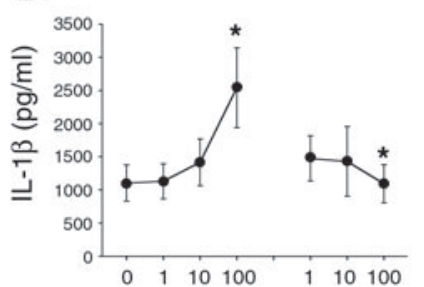

C
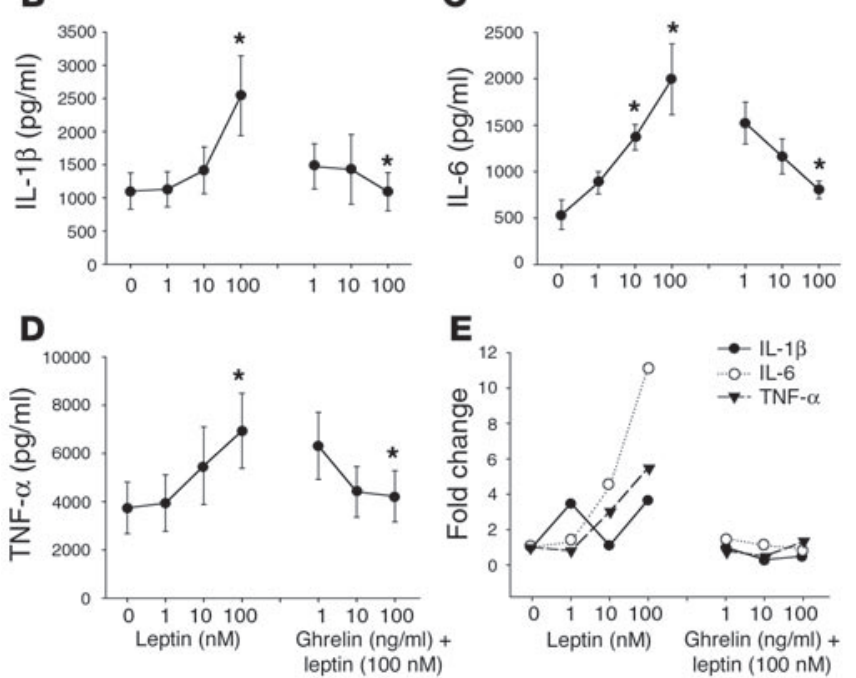

Figure 4

Ghrelin inhibits leptin-induced increase in inflammatory cytokines. (A) The localization of the leptin receptor (Ob-R) on the surface of human T cells. (B-D) Anti-CD3 mAb-activated T cells from human adult donors $(n=6)$ were incubated with various concentration of leptin or coincubated with various doses of ghrelin with a biologically optimal concentration of leptin (100 nM). Cytokine production and mRNA expression was evaluated after 24 hours of culture. The cytokines examined were (B) IL-1 $\beta$, (C) IL-6, and (D) TNF- $\alpha$. (E) Fold change in IL-1 $\beta, I L-6$, and TNF- $\alpha$ mRNA expression after normalization with GAPDH and measured by real-time RT-PCR. Values are expressed as mean \pm SEM $\left({ }^{*} P<0.05\right)$.

ure 5G). Lymphoid organs and small intestines expressed ghrelin mRNA levels fivefold higher than did placenta.

Ghrelin downregulates inflammatory cytokine expression and anorexia in response to endotoxin challenge. Bacterial LPS, the principal component in the pathogenesis of endotoxic shock, acts primarily on monocytes and evokes an acute phase response in vivo, resulting in excessive production of IL- $1 \beta$, IL- 6 , and TNF- $\alpha$. The amplification of these proximal cytokines has a broad array of proinflammatory and anorexigenic effects $(12,13)$, contributing to pathogenesis of sepsis and multiple organ failure $(30,31)$. In an effort to examine the ability of ghrelin to modulate inflammatory cytokine expression in vivo, we treated mice with ghrelin prior to and after LPS administration. As shown in Figure 6, ghrelin exerted a potent antiinflammatory effect on LPS-induced endotoxemia, with inhibition of IL- $1 \beta$, IL- 6 , and TNF- $\alpha$ expression in vivo. Real-time PCR analysis of mRNA derived from the spleen and liver of these endotoxintreated mice revealed a strong induction of these cytokine genes 4 hours after LPS administration (Figure 6, A-C), with a significant diminishment in mRNA expression by 24 hours (Figure 6, D-F). Mice treated with ghrelin and challenged with endotoxin demon- strated an attenuation of IL- $1 \beta$ and IL- 6 mRNA expression in both spleen and liver after 4 and 24 hours (Figure 6, A-F). Attenuation of TNF- $\alpha$ mRNA was observed in both spleen and liver at 4 hours (Figure 6C); TNF- $\alpha$ expression was also inhibited in liver 24 hours after LPS administration and remained unchanged in spleen (Figure $6 \mathrm{~F}$ ). Similar inhibition of proinflammatory cytokines was observed in lungs and mesenteric lymph nodes of ghrelin-treated mice 4-24 hours after LPS challenge (data not shown).

To measure circulating serum cytokine levels, mice were treated with LPS and then with ghrelin for either 4 or 24 hours. Analysis of the serum cytokine levels revealed a significant change in circulating TNF- $\alpha$ (Figure 7C), but not in IL-1 $\beta$ (Figure 7A) or IL-6 (Figure $7 \mathrm{~B})$, levels at 4 hours after ghrelin treatment; however, a significant inhibition of IL- $1 \beta$ and IL- 6 was observed 24 hours after LPS challenge (Figure 7, D and E). TNF- $\alpha$ levels were undetectable in the serum 24 hours after LPS challenge. To examine the effects of ghrelin on endotoxin-induced anorexia, food intake was also assessed at 24 hours after ghrelin and/or LPS administration. While the LPS-challenged mice demonstrated a dramatic diminishment in food consumption compared with sham-treated mice (80\%), prior ghrelin treatment resulted in a significant attenuation of this LPSinduced anorexia (Figure 7F). As expected, ghrelin-treated control mice in the absence of LPS challenge also demonstrated a significant increase in food intake $(30 \%)$ compared with sham-treated controls (data not shown). Interestingly, serum IL-1 $\beta$ and IL- $1 \alpha$ levels were also significantly inhibited in these mice infused with ghrelin alone when compared with sham-treated control mice (Figure 7, G-H), and serum IL-1 $\alpha$ levels were inhibited 24 hours after LPS and ghrelin treatment (Figure 7H). Neither LPS nor ghrelin treatment altered serum leptin levels in these mice (data not shown).

\section{Discussion}

We believe this to be the first report to demonstrate that ghrelin, via functional cell surface GHS-R, exerts both specific and selective inhibitory effects on the expression and production of the inflammatory cytokines IL-1 $\beta$, IL- 6 , and TNF- $\alpha$ by human PBMCs and T cells. GHS-Rs on primary and cultured human T cells, similar to other classical GPCRs, elicit a potent intracellular calcium release upon ligation with their natural ligand, ghrelin, and are preferentially associated with $\mathrm{GM} 1^{+}$lipid rafts upon cellular activation. We also observed that, consistent with expression of functional GHS-R ghrelin on T cells, ghrelin actively induces actin polymerization within human T cells. Similar to treatment with chemokines (SDF-1 $\alpha$ ), ghrelin treatment led to the cellular polarization of leukocytes and actin distribution changes from a linear cortical pattern in resting lymphocytes to more concentrated patterns at the leading edge and contact zones in polarized and activated T cells $(19,20)$. These GPCR-like redistribution patterns also support a potential role for GHS-R in immune cell signaling and trafficking.

There is increasing evidence that the immune system - in particular the production of inflammatory cytokines by leukocytes - may play an important role in the development of anorexiacachexia syndrome (11-13). The cytokines considered to be the most relevant to inflammatory anorexia include IL-1 $\beta$, IL-6, and TNF- $\alpha$. Peripherally administered ghrelin has been shown to block IL-1 $\beta$-induced anorexia (29) and produces positive energy balance by promoting food intake and decreasing energy expenditure. Our current data demonstrates an inhibitory effect of ghrelin on proinflammatory cytokine expression, supporting a possible 
A

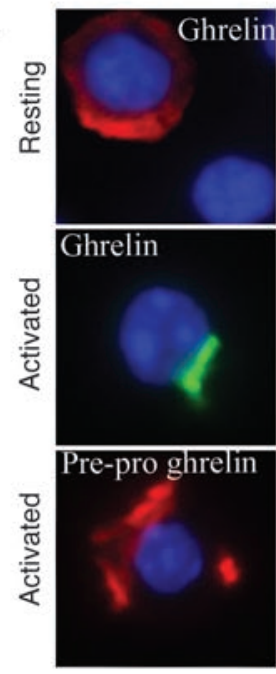

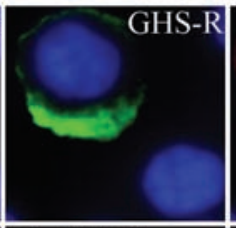
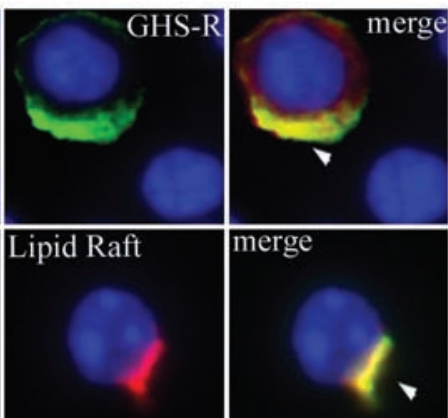

merge

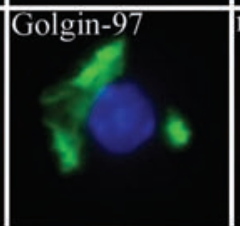

$\mathbf{F}$

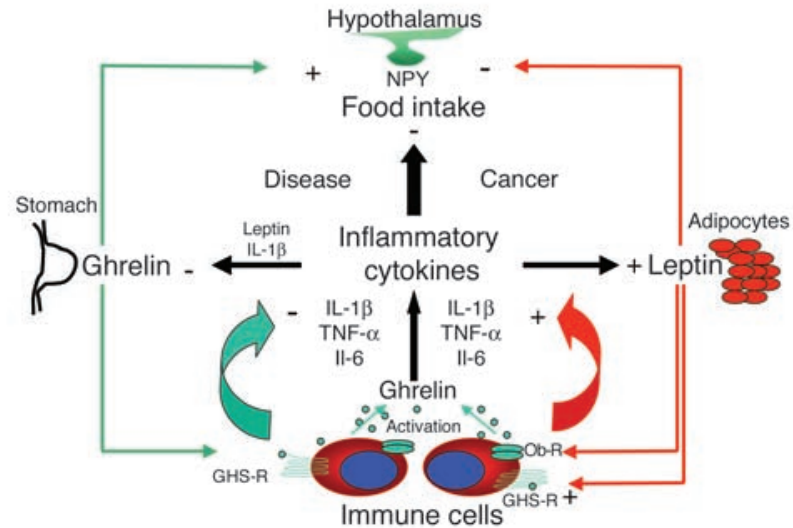

B
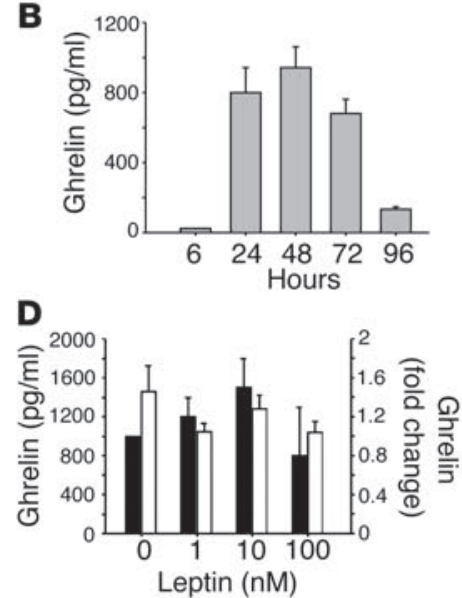

G

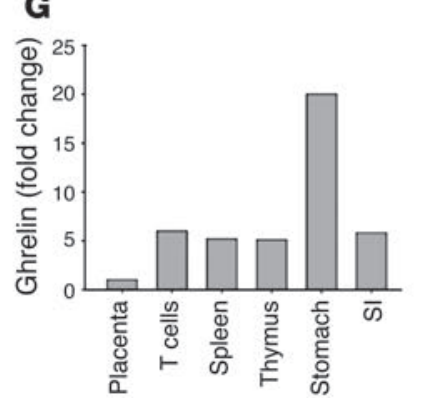

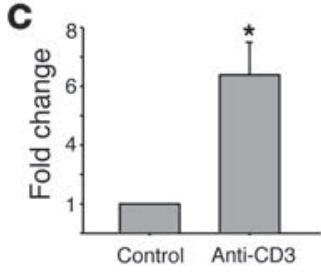

E

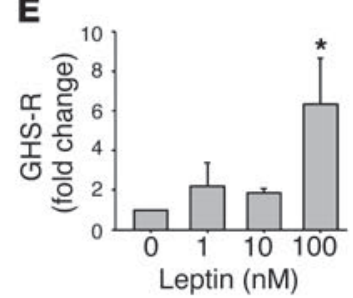

\section{Figure 5}

Ghrelin is expressed and secreted from human T cells. (A) Ghrelin and GHS-R coexpression in resting T cells (upper row); activated T cells demonstrating that ghrelin is strongly colocalized in $\mathrm{GM} 1^{+}$lipid rafts (middle row); preproghrelin colocalizes in Golgi bodies in activated human T cells (lower row). (B) Kinetics of ghrelin secretion from anti-CD3 mAb-stimulated T cells. (C) Fold change in ghrelin mRNA levels upon T cell activation as assessed by real time RT-PCR analysis. Values are expressed as mean \pm SEM ( $\left.{ }^{*} P<0.05\right)$. (D) Ghrelin expression was quantitated in T cells stimulated in presence of immobilized anti-CD3 antibody and in the presence or absence of different concentrations of leptin after 24 hours in culture. Fold change in ghrelin mRNA expression (black bars) after normalization with GAPDH and measured by real time RT-PCR. Ghrelin protein production was determined by EIA (white bars). (E) Fold change in GHS-R gene expression after normalization with GAPDH ( $n=6$ ), with values expressed as mean \pm SEM $\left({ }^{*} P<0.05\right)$. (F) Hypothetical model for functional role of ghrelin as a signal linking the immune and endocrine systems in control of food intake. (G) Comparative ghrelin mRNA expression in stomach as compared to lymphoid organs. SI, small intestine.

regulatory role for ghrelin and GHS-R in controlling cytokineinduced anorexia. Moreover, the combination of IL-1 $\beta$ and leptin has also been shown to inhibit ghrelin expression in stomach (29), and stomach ghrelin expression is increased in leptin-deficient mice. Leptin and ghrelin are considered to exert mutually antagonistic effects on the food intake at the hypothalamic level $(4,6)$. Leptin, a member of gp130 family of cytokines, induces a strong Th1 response (25) and is regarded as a proinflammatory inducer (22-26). Leptin's actions on food intake are controlled, in part, by an increase in the level of IL-1 $\beta$ in the hypothalamus (32). Similarly, anorectic effects of IL-1 are mediated via increasing leptin levels (33). However, the relationship between leptin and ghrelin at the level of immune cells is completely unknown.

We demonstrate here that leptin can directly induce the mRNA expression and secretion of IL- $1 \beta$, IL- 6 , and TNF- $\alpha$ by human T cells and PBMCs. Leptin and several other gp130 ligands includ- ing LIF, CNTF, and IL-6 all appear to exert similar effects on host metabolism $(34,35)$. Moreover, IL-6-deficient mice, in a fashion similar to leptin-deficient mice, develop obesity (36). While leptin has been shown to be associated with cachexia, leptin levels are not elevated in many cancer-associated wasting conditions (37), most likely due to a systemic decline in adipose tissue. However, cachexia seen in chronic heart failure patients is associated with hyperleptinemia (38). In contrast, ghrelin attenuates cachexia associated with chronic heart failure in rats (39), and the GHS-R analogue, GHRP-2, counteracts protein hypercatabolism, skeletal muscle proteolysis, and osteoporosis in critically ill patients with wasting condition (40). It has recently been reported that an increase in the level of circulating leptin within a murine MS model regulates inflammatory anorexia and disease susceptibility (41). Moreover, fasting-induced suppression of leptin levels dramatically attenuates the onset of experimental autoimmune 

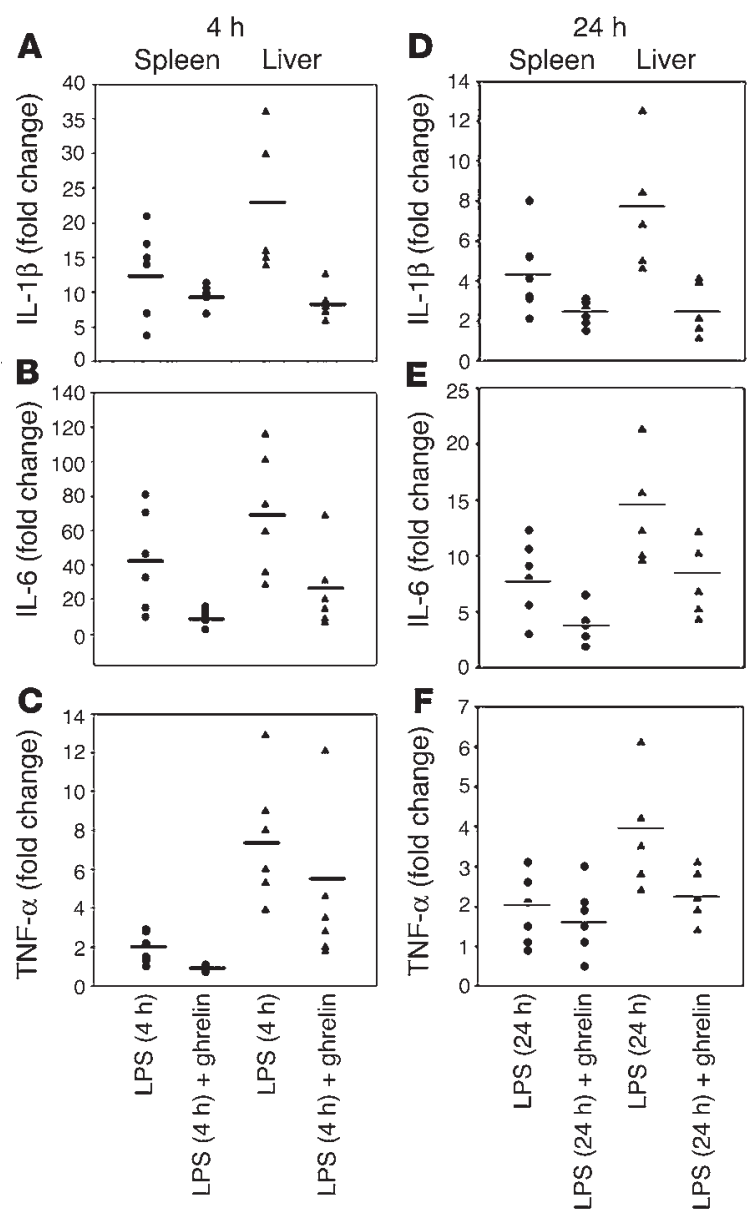

encephalomyelitis (EAE) in this model (41). Given that fasting is associated with a decrease in serum leptin and a strong increase in circulating ghrelin levels $(5,6)$, it seems feasible that the observed anti-inflammatory effects of fasting in this murine MS model may also be mediated, in part, by ghrelin. Furthermore, it has recently been demonstrated that NPY attenuates Th1-mediated induction of EAE (42). Given that fasting and ghrelin induce NPY, it seems likely that the orexigenic axis might play a critical role in regulating endogenous inflammatory responses. Ghrelin has now been recognized to have pleiotropic functions in a variety of organ systems; however, studies by Smith and colleagues (43) have demonstrated no physiological abnormalities in a ghrelin knockout mouse, suggesting involvement of some possible compensatory mechanisms regulated by other orexigens.

Because regulation of hunger is most critical for the survival of species, a complex circuitry of compensatory and overlapping mechanisms has evolved to protect the host against deficiency in one or more of these regulators. Similar genetic approaches to study the other potent orexigens such as NPY and agouti-related peptide have also failed to yield a definite phenotype (44). Therefore, additional controlled studies in orexigens or their receptor knockout mouse models in response to stress, inflammation, or pathogenic challenge might shed more light and reveal additional unique and overlapping functions of these orexigens.

To date, ghrelin has only been reported to be produced by endocrine-like cells in the stomach and subsequently released into the peripheral circulation. Through a number of analytical techniques,

\section{Figure 6}

Ghrelin inhibits inflammatory cytokine expression and anorexia in a murine endotoxemia model. Real-time PCR analysis of inflammatory cytokine mRNA in spleen and liver 4 and 24 hours after LPS and ghrelin administration in BALB/c mice. Ct values for cytokines were normalized with GAPDH and expressed as fold change over collapsed values for sham-treated, control mice $(n=6)$. At 4 and 24 hours post LPS injection, ghrelin inhibits IL-1 $\beta$ (A and D) and IL-6 (B and E) transcription in both spleen and liver. TNF- $\alpha$ mRNA expression was attenuated at 4 hours after LPS in spleen, but ghrelin failed to further inhibit TNF- $\alpha$ in spleen at 24 hours. However, ghrelin continued to significantly suppress TNF- $\alpha$ mRNA in liver (C and $\mathbf{F})$.

we demonstrate here that ghrelin is endogenously produced and secreted by both $\mathrm{T}$ cells and PBMCs in a fashion similar to many immune-derived cytokines. The majority of T cells examined from human donors were found to constitutively express low levels of endogenous ghrelin, which is significantly increased upon cellular activation. This high percentage of ghrelin-positive cells may also be due to the fact that our anti-ghrelin antibody recognized both the mature as well as the 117-amino-acid preproghrelin forms. However, the preproghrelin antibody does not bind the mature peptide, and subcellular localization revealed tight colocalization of preproghrelin in the Golgi apparatus. Activated T cells express and secrete the ghrelin protein, which strongly suggests that prepro peptide must be actively cleaved in T cells to yield the active ghrelin peptide. Similar to several cytokines (e.g., TGF- $\beta$ ) and hormones (e.g., thyroid stimulating hormone), these precursor proteins are synthesized and subsequently stored for immediate cleavage and use when needed. Furthermore, we also demonstrate the expression and secretion of the mature form of ghrelin from $\mathrm{T}$ cells after activation via TCR ligation. Gastrectomy results in only a $35-50 \%$ decline in circulating ghrelin, and ghrelin levels increase to two thirds of pre-gastrectomy levels in human subjects, which suggests that other tissues compensate for maintaining the peripheral ghrelin levels (27). Secretion of ghrelin from T cells suggests that immune cell-derived ghrelin might make up part of residual concentration of circulating ghrelin. In addition, ghrelin is also regarded as the only known hormone where the hydroxyl group of the third serine residue is acylated by $n$-octanoic acid, and this acylation is critical for some of the biological activities of this polypeptide (1). N-terminal acylated peptides are known to preferentially aggregate in cholesterol rich microdomains (45), and, interestingly, we observed that ghrelin immunoreactivity in activated T cells is highly colocalized within cholesterol-rich GM1+ domains. These results suggest that ghrelin may be selectively targeted to the plasma membrane to facilitate interaction with its own transmembrane receptor to optimally mediate receptor-ligand interactions. Such a pathway would have strong implications regarding the role of ghrelin in the control of immune responses. In addition, it seems likely that localized production of ghrelin may play a critical role in the immediate control of ongoing and leptin-mediated responses within the local microenvironment.

LPS-induced endotoxemia in mice is a well-recognized model for inducing septic shock and is also associated with anorexia due to excessive production of proinflammatory mediators. In spite of a large body of data, the causes of systemic inflammatory response syndrome (SIRS) remain unknown, and various therapeutic approaches have yielded minimal beneficial results $(30,31)$. LPS directly acts on mononuclear cells, but the resultant 
endotoxemia also affects a wide variety of cells and systems and is associated with a refractory catabolic state. Because ghrelin receptors are ubiquitously expressed in monocytes (Figure 2), B cells, and dendritic cells (data not shown) and that ghrelin inhibits inflammatory cytokines in human mononuclear cells as well as monocytes, we utilized an established murine model of LPSinduced endotoxemia (46). We demonstrate that ghrelin infusions in LPS-challenged mice lead to a significant inhibition of proinflammatory cytokines IL- $1 \alpha$ and IL- $\beta$, IL- 6 , and TNF- $\alpha$ in circulation as well as in liver, spleen, lungs, and mesenteric lymph nodes. In addition, LPS-induced endotoxemia results in inhibition of ghrelin secretion (47), and ghrelin infusion increases body weight in septic animals (48). Considering the data presented herein, it seems plausible that inhibition of ghrelin secretion after LPS challenge might exacerbate the ongoing inflammatory insult and promote development of a catabolic state. Furthermore, we demonstrated that LPS-induced inflammatory anorexia is also significantly reduced in ghrelin-treated mice. These data strongly support possible inclusion of ghrelin and synthetic GHS as potential candidates in treatment of SIRS. Ghrelin might also have a regulatory role in chronic conditions such as Helicobacter pylori infection, where persisting gastric inflammation is associated with lower ghrelin levels (49) and correction of infection leads to up regulation of ghrelin secretion.

Our current studies suggest that ghrelin functions as a vital counterregulatory signal in the immune system, controlling not only activation-induced cytokine expression but also leptininduced expression of these same inflammatory mediators. The reciprocal regulatory effects of these hormones on expression of IL-1 $\beta$, IL-6, and TNF- $\alpha$ by immune cells may have widespread implications in the development of wasting diseases, aging, and frailty. Proposed interventions to lower ghrelin levels or to block GHS-R for treatment of obesity may result in a potentiation of ongoing inflammatory insults or lead to immune dysregulation. On the contrary, the novel anti-inflammatory actions of ghrelin within the immune system may have potential benefits in management of anorexia-cachexia syndrome associated with a wide range of inflammatory conditions and cancer.

\section{Methods}

Human subjects. Pheresis packs were prepared from six healthy male donors between 22 and 37 years age for the isolation of PBMCs and T cells. The average BMI of our donors is 24.6 and is within the normal range (18.5-24.9).

Mice. Male BALB/c mice (Taconic, Germantown, New York, USA), 8-10 weeks old and weighing 20-22 g, were used. The guidelines proposed by the committee for the Care and Use of Laboratory Animal Resources, Commission of Life Sciences, National Research Council, were followed to minimize animal pain and distress. Each animal received rodent laboratory chow and ad libitum water.

LPS-induced inflammation. Endotoxin shock in mice was induced by intraperitoneal (i.p.) injection with $10 \mu$ g of LPS (E. coli serotype 055:B5; Sigma-Aldrich, St. Louis, Missouri, USA) as described previously (46). Animals also received a single i.p. injection of ghrelin in PBS at 24 hours 30 minutes prior to LPS administration. Mice were sacrificed 4 and 24 hours after LPS challenge, and visceral organs and serum were collected.

Tcell isolation and culture. PBMCs were obtained by Ficoll-Hypaque density centrifugation. T cells were purified from PBMCs using human $\mathrm{T}$ cell enrichment columns (R\&D Systems, Minneapolis,
Minnesota, USA) via high-affinity negative selection according to the manufacturer's instructions. Flow cytometric analysis typically revealed greater than $90 \%$ purity. T cells were stimulated with plate bound anti-human CD3 antibody (BD Pharmingen, San Diego, California, USA) $(200 \mathrm{ng} / \mathrm{ml})$ at a concentration of $3 \times 10^{6}$ cells/ $\mathrm{ml}$ in AIM-V (Gibco-BRL, Carlsbad, California, USA) serum-free media for 24 hours. Ghrelin 1-18 octanoylated fragment (Peptide International, Louisville, Kentucky, USA) was used to treat the cell in culture; this fragment was found to elicit biological effects comparable to the intracellular calcium release and cytokine expression induced by full-length octanoylated peptide.

Immunofluorescence staining. Cellular staining was performed as described previously (50). Briefly, cells were incubated with different combinations of human anti-GHS-R goat IgG, antiGHS-R rabbit IgG recognizing 186-202 amino acids near the C terminus of human GHS-R (Santa Cruz Biotech, Santa Cruz, California, USA), anti-total ghrelin rabbit IgG, anti-preproghre-
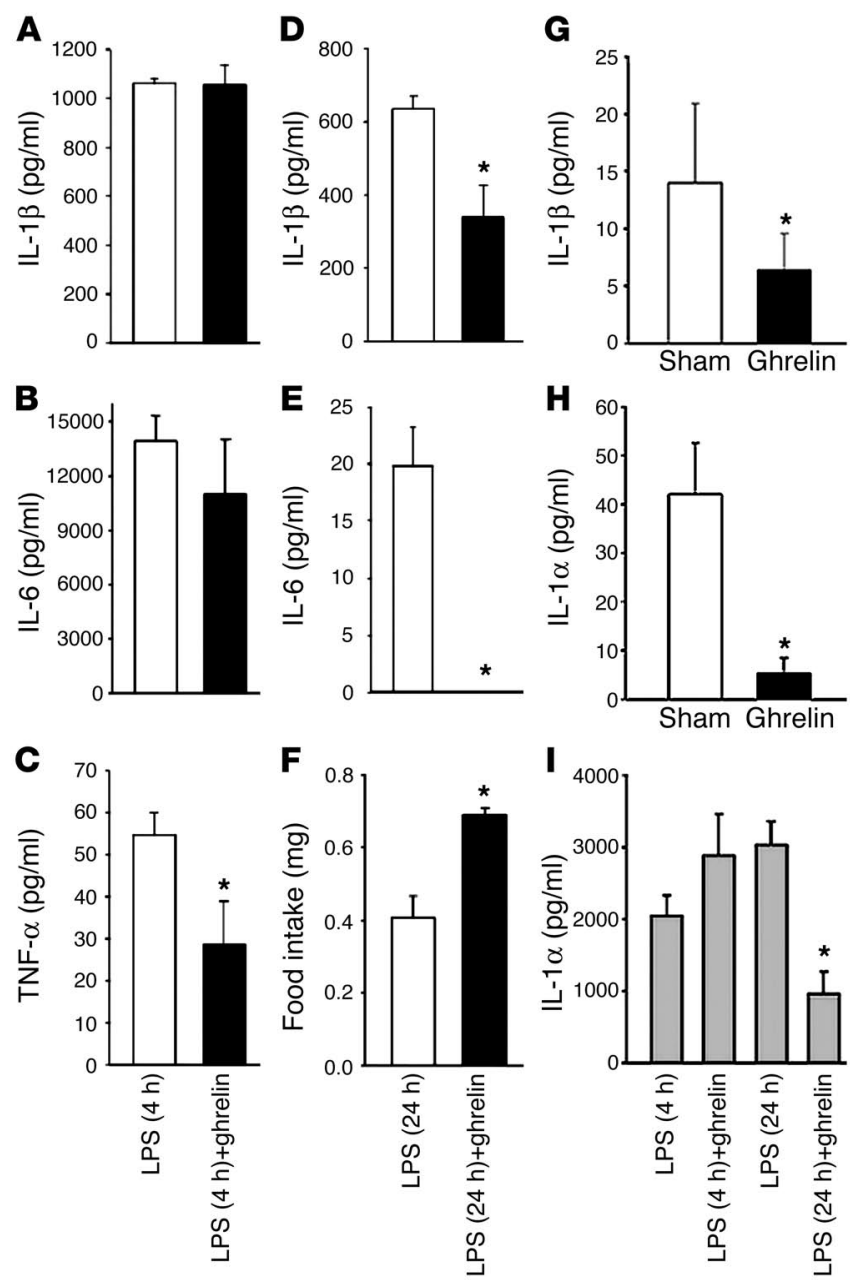

\section{Figure 7}

Cytokine levels in the serum of treated mice after LPS and ghrelin treatment. Cytokines tested were IL-1 $\beta$ (A), IL-6 (B), and TNF- $\alpha(\mathbf{C})$ at 4 hours and IL-1 $\beta$ (D) and IL-6 (E) at 24 hours. Ghrelin stimulates food intake in LPS challenged mice (F). Ghrelin treatment inhibits basal IL-1 $\beta$ and IL- $1 \alpha$ secretion in periphery $(\mathbf{G}$ and $\mathbf{H})$. Ghrelin also inhibits serum IL- $1 \alpha$ levels 24 hours after LPS challenge (I). Values are expressed as mean \pm SEM $\left({ }^{*} P<0.05\right)$. 
lin rabbit IgG (Phoenix Peptides, Belmont, California, USA), anti-acylated guinea pig antibody (Linco Research Inc., St. Charles, Missouri, USA) overnight at $4{ }^{\circ} \mathrm{C}$. Lipid rafts were visualized using cholera toxin-Alexa Fluor-594 (AF-594) (Molecular Probes, Eugene, Oregon, USA) at $20 \mu \mathrm{g} / \mathrm{ml}$ for 45 minutes. Golgi bodies were stained with goat anti-mouse Golgin-97, a marker for Golgi bodies (Molecular Probes). Cells were thereafter labeled with appropriate secondary antibodies conjugated to AF-488 and AF-594. Nuclei were counterstained using DAPI (1 $\mu \mathrm{g} / \mathrm{ml}$ ). Images were acquired by Spot Advanced software (Diagnostic Instruments Inc., Sterling Heights, Michigan, USA) on a Zeiss Axiovert S100 microscope under a $\times 100$ objective lens (Carl Zeiss, Thornwood, New York, USA).

Flow cytometric analysis. Human PBMCs $\left(1 \times 10^{6}\right)$ in PBS containing $2 \%$ heat-inactivated FBS were fixed using $1 \%$ paraformaldehyde and stained for CD3 APC-, CD4 PE-, CD8 PE-, and CD14 PE-conjugated antibodies (BD Pharmingen) and incubated for $30 \mathrm{~min}$ utes on ice. Cells were washed with PBS, stained for GHS-R and ghrelin, and labeled with specific secondary antibodies conjugated to AF-488; then analyzed on a FACScan cytometer (BD, Franklin Lakes, New Jersey, USA).

Intracellular calcium mobilization. Measurement of intracellular calcium release in response to ghrelin and SDF-1 was performed as described previously (17). Purified human T cells were activated via TCR ligation for 24 hours and expanded in the presence of IL-2 (10 U/ml) for 3-4 days in RPMI 1640 supplemented with 10\% FCS, $2 \%$ human serum, $5 \times 10^{-5} \mathrm{M} 2$-mercapthoethanol, $1 \mathrm{mM}$ L-glutamine, $1 \mathrm{mM}$ sodium pyruvate, $0.1 \mathrm{mM}$ nonessential amino acids, penicillin $(100 \mathrm{U} / \mathrm{ml})$, and streptomycin $(100 \mu \mathrm{g} / \mathrm{ml})$ (SigmaAldrich). Cells were incubated in PBS containing $5 \mathrm{mM}$ Fura-2 acetoxymethyl ester (Molecular Probes) for 30 minutes at room temperature. The cells were subsequently washed and then resuspended at $1 \times 10^{6} / \mathrm{ml}$ in PBS. A total of $2 \mathrm{ml}$ of the cell suspension was placed in a continuously stirring cuvette at room temperature in an LS50B spectrophotometer (Perkin-Elmer, Wellesley, Massachusetts, USA). Fluorescence was monitored at $\lambda_{\mathrm{ex} 1}=340 \mathrm{~nm}$, $\lambda_{\mathrm{ex} 2}=380 \mathrm{~nm}$, and $\lambda_{\mathrm{em}}=510 \mathrm{~nm}$. The data are presented as the relative ratio of fluorescence excited at 340 and $380 \mathrm{~nm}$.

Actin polymerization. Human T cells were incubated either with ghrelin $(100 \mathrm{ng} / \mathrm{ml})$ or positive control SDF-1 $(100 \mathrm{ng} / \mathrm{ml})$ for $20 \mathrm{~min}$. Thereafter, cells were fixed and permeabilized in $2 \%$ paraformaldehyde plus $0.1 \%$ Triton-X 100 and stained for actin using phalloidin AF-594 and nucleus by DAPI.

Cytokine estimation. IL-1 $\beta$, IL-6, and TNF- $\alpha$ were estimated in $\mathrm{T}$ cell supernatants after 24 hours using commercial ELISA kits according to manufacturer's instructions (Biosource, Camarillo, California, USA). Serum cytokines were analyzed using Bio-
Plex Mouse Cytokine 18-Plex Panel according to manufacturers instructions (Biorad Laboratories, Hercules, California, USA).

Ghrelin estimation. Immunoreactive ghrelin was measured in duplicate with an ELISA using a rabbit polyclonal antibody against fulllength, octanoylated human ghrelin that recognizes the acylated and des-acyl forms of the hormone $(3,5)$ (Phoenix Pharmaceuticals, Belmont, California, USA). Active ghrelin was estimated using RIA (Linco Research Inc.) according to manufacturer's instruction.

Real Time RT-PCR analysis. RT-PCR was performed as described previously (51). Total RNA ( $2 \mu \mathrm{g})$ and oligo-dT primers were used to synthesize single-stranded cDNA using the Reverse Transcription kit (Life Technologies, Gaithersburg, Maryland, USA) according to manufacturer's instructions. The PCR was set up using SYBR green Master Mix (Applied Biosystems, Foster City, California, USA), $1 \mu \mathrm{l} \mathrm{cDNA}$, and gene-specific primers at a final concentration of $0.3 \mu \mathrm{M}$. Thermal cycling was carried out on the Applied Biosystems GeneAmp 7700 Sequence Detector, and SYBR green dye intensity was analyzed using GeneAmp 7700 SDS software. Primers for human IL-1 $\beta$, IL-6, and TNF- $\alpha$ genes and GAPDH as control were purchased from Biosource International (Camarillo, California, USA); human GHS-R 1a and ghrelin were used as described previously (9). Mouse IL- $1 \beta$, IL-6, TNF- $\alpha$, GAPDH, and human GHS-R 1a primers were designed using ABI prism software (Applied Biosystems). The PCR product of the GHS-R 1a amplification was quantitated using the Agilent 2100 Bioanalyzer (Agilent Technologies). Primers are available upon request. No PCR products were generated from genomic versus cDNA template.

Statistical analysis. Results were expressed as the mean \pm SEM. Statistical analysis was carried out by one-way ANOVA. Significant differences between treatment groups were determined by the StudentNewman-Keuls test; statistical significance was inferred at $P<0.05$.

\section{Acknowledgments}

We thank the NIA Flow Cytometry Laboratory and Pheresis Unit for their assistance. We also thank Dan Longo and Ashani Weeraratna (NIA), and Nahid Parvizi (Institut für Tierzucht und Tierverhalten, Neustadt, Germany), for valuable input and discussions. We thank Igor Espinoza's laboratory at NIA for providing us some of the purified monocytes utilized in our studies.

Received for publication January 21, 2004, and accepted in revised form April 27, 2004.

Address correspondence to: Dennis D. Taub, Laboratory of Immunology, National Institute on Aging, NIH, 5600 Nathan Shock Drive, Baltimore, Maryland, 21224, USA. Phone: (410) 558-8181; Fax: (410) 558-8284; E-mail: TaubD@grc.nia.nih.gov.
1. Kojima, M., et al. 1999. Ghrelin is a growth-hormone-releasing acylated peptide from stomach. Nature. 402:656-660.

2. Date, Y., et al. 2000. Ghrelin, a novel growth hormone-releasing acylated peptide, is synthesized in a distinct endocrine cell type in the gastrointestinal tracts of rats and humans. Endocrinology. 141:4255-4261.

3. Tschop, M., Smiley, D.L., and Heiman, M.L. 2000. Ghrelin induces adiposity in rodents. Nature. 407:908-913.

4. Nakazato, M., et al. 2001. A role for ghrelin in the central regulation of feeding. Nature. 409:194-198.

5. Cummings, D.E., et al. 2002. Human plasma ghrelin levels after diet-induced weight loss and gastric bypass surgery. N. Engl. J. Med. 346:1623-1630.
6. Inui, A. 2001. Ghrelin: An orexigenic and somatotrophic signal from the stomach. Nat. Rev. Neurosci. 2:551-560.

7. Howard, A.D., et al. 1996. A receptor in pituitary and hypothalamus that functions in growth hormone release. Science. 273:974-977.

8. Palyha, O.C., et al. 2000. Ligand activation of human orphan growth hormone (GH) secretagogue receptor (GHS-R) conserved from pufferfish to humans. Mol. Endocrinol. 14:160-169.

9. Gnanapavan, S., et al. 2002. The tissue distribution of the mRNA of ghrelin and subtypes of its receptor, GHS-R, in humans. J. Clin. Endocrinol. Metab. 87:2988-2991.

10. Poppi, L., et al. 2002. Growth hormone secretagogue analogue hexarelin stimulates $\mathrm{GH}$ from peripheral lymphocytes. Exp. Clin. Endocrinol. Diabetes. 110:343-347.

11. Dantzer, R. 2001. Cytokine induced sickness behaviour: Mechanisms and implications. Ann. N. Y. Acad. Sci. 933:222-234.

12. Hart, B.L. 1988. Biological basis of the behaviour of sick animals. Neurosci. Biobehav. Rev. 12:123-137.

13. Kotler, D.P. 2000. Cachexia. Ann. Intern. Med. 133:622-634.

14. Ershler, W.B., and Keller, T.E. 2000. Age-associated increased interleukin- 6 gene expression, late life diseases, and frailty. Annu. Rev. Med. 51:245-270.

15. Bruunsgaard, H., Pedersen, M., and Pedersen, B.K. 2001. Ageing and proinflammatory cytokines. Curr. Opin. Hematol. 8:131-136.

16. McCarty, M.F. 1999. Interleukin-6 as a central 
mediator of cardiovascular risk associated with chronic inflammation, smoking, diabetes, and visceral obesity: down regulation with essential fatty acids, ethanol, and pentoxifylline. Med. Hypotheses. 52:465-477.

17. Nguyen, D.H., and Taub, D. 2002. Cholesterol is essential for macrophage inflammatory protein 1 beta binding and conformational integrity of CC chemokine receptor 5. Blood. 99:4298-4306.

18. Nagasawa, T., Tachibana, K., and Kawabata, K. 1999. A CXC chemokine SDF-1/PBSF: a ligand for a HIV coreceptor, CXCR4. Adv. Immunol. 71:211-228.

19. Sanchez-Madrid, F., and del Pozo, M.A. 1999. Leukocyte polarization in cell migration and immune interaction. EMBO J. 18:501-511.

20. Taub, D.D., Conlon, K., Lloyd, A.R., Oppenheim, J.J., and Kelvin, D.J. 1993. Preferential migration of activated $\mathrm{CD} 4^{+}$and $\mathrm{CD} 8^{+} \mathrm{T}$ cells in response to MIP-1 alpha and MIP-1 beta. Science. 260:355-358.

21. Inui, A. 1999. Cancer anorexia-cachexia syndrome: are neuropeptides the key. Cancer Res. 59:4493-4501

22. Faggioni, R., et al. 2000. Leptin deficient (ob/ob) mice are protected from $\mathrm{T}$ cell-mediated hepatotoxicity: Role of tumor necrosis factor $\alpha$ and IL-18. Proc. Natl. Acad. Sci. U. S. A. 97:2367-2372.

23. Loffreda, S., et al. 1998. Leptin regulates proinflammatory immune responses. FASEB J. 12:57-65.

24. Zarkesh-Esfahani, H., et al. 2001. High dose leptin activates human leukocytes via receptor expression on monocytes. J. Immunol. 167:4593-4599.

25. Lord, G.M., et al. 1998. Leptin modulates the T-cell immune response and reverses starvation-induced immunosuppression. Nature. 394:897-901.

26. Dixit, V.D., Mielenz, M., Taub, D., and Parvizi, N 2003. Leptin induces growth hormone secretion from peripheral blood mononuclear cells via a protein kinase $\mathrm{C}$ and nitric oxide dependent mechanism. Endocrinology. 144:5595-5603.

27. Hosoda, H., Kojima, M., Mizushima, T., Shimizu, S., and Kangawa, K. 2003. Structural divergence of human ghrelin; identification of multiple ghrelinderived molecules produced by post-translational processing. J. Biol. Chem. 278:64-70.

28. Taub, D.D., et al. 1994. Growth hormone promotes human $\mathrm{T}$ cell adhesion and migration to both human and murine matrix proteins in vitro and directly promotes xenogeneic engraftment. J. Clin. Invest. 94:293-300.

29. Asakawa, A., et al. 2001. Ghrelin is an appetitestimulatory signal from stomach with structural resemblance to motilin. Gastroenterology. 120:337-345.

30. Cohen, J. 2003. The immunopathogenesis of sepsis. Nature. 420:885-891.

31. Riedemann, N.C, Guo, R.F, and Ward, P.A. 2003. The enigma of sepsis. J. Clin. Invest. 112:460-467. doi:10.1172/JCI200319523.

32. Luheshi, G.N., Gardner, J.D., Rushforth, D.A., Loudon, A.S., and Rothwell, N.J. 1999. Leptin actions on food intake and body temperature are mediated by IL-1. Proc. Natl. Acad. Sci. U. S. A. 96:7047-7052.

33. Janik, J.E., et al. 1997. Interleukin $1 \alpha$ increases serum leptin concentration in humans. J. Clin. Endocrinol. Metab. 82:3084-3086.

34. Lambert, P.D., et al. 2001. Ciliary neurotrophic factor activates leptin-like pathways and reduces body fat, without cachexia or rebound weight gain, even in leptin-resistant obesity. Proc. Natl. Acad. Sci.U.S. A. 98:4652-4657.

35. Beretta, E., Dhillon, H., Kalra, P.S., and Kalra, S.P. 2002. Central LIF gene therapy suppresses food intake, body weight, serum leptin and insulin for extended periods. Peptides. 23:975-984

36. Wallenius, V., et al. 2002. Interleukin-6-deficient mice develop mature-onset obesity. Nat. Med. 8:75-79.

37. Laviano, A., Russo, M., Freda, F., and Rossi-Fanelli, F. 2002. Neurochemical mechanisms for cancer anorexia. Nutrition. 18:100-105.

38. Doehner, W., et al. 2001. Leptin, insulin sensitivity and growth hormone binding protein in chronic heart failure with and without cardiac cachexia. Eur. J. Endocrinol. 145:727-735.

39. Nagaya, N., et al. 2001. Chronic administration of ghrelin improves left ventricular dysfunction and attenuates development of cardiac cachexia in rats with heart failure. Circulation. 104:1430-1435.

40. Van den Berghe, G., et al. 1999. Reactivation of pituitary hormone release and metabolic improvement by infusion of growth hormone-releasing peptide and thyrotropin-releasing hormone in patients with protracted critical illness. J. Clin. Endocrinol. Metab. 84:1311-1323.

41. Sanna, V., et al. 2003. Leptin surge precedes onset of autoimmune encephalomyelitis and correlates with development of pathogenic T cell responses. J. Clin. Invest. 111:241-250. doi:10.1172/JCI200316721.

42. Bedoui, S., et al. 2003. Neuropeptide Y (NPY) suppresses experimental autoimmune encephalomyelitis: NPY1 receptor-specific inhibition of autoreactive Th1 responses in vivo. J. Immunol. 171:3451-3458

43. Sun, Y., Ahmed, S., and Smith, R.G. 2003. Deletion of ghrelin impairs neither growth nor appetite. Mol. Cell. Biol. 23:7973-7981.

44. Qian, S., et al. 2002. Neither agouti-related protein nor neuropeptide $\mathrm{Y}$ is critically required for the regulation of energy homeostasis in mice. Mol. Cell. Biol. 22:5027-5035.

45. McCabe, J.B., and Berthiaume, L.G. 2001. N-terminal acylation confers localization to cholesterol, sphingolipid-enriched membranes but not to lipid rafts/caveolae. Mol. Biol. Cell. 12:3601-3617.

46. Bochkov, V.N., et al. 2002. Protective role of phospholipid oxidation products in endotoxin-induced tissue damage. Nature. 419:77-81.

47. Basa, N.R., et al. 2003. Bacterial lipopolysaccharide shifts fasted plasma ghrelin to postprandial levels in rats. Neurosci. Lett. 343:25-28.

48. Hataya, Y., et al. 2003. Alterations of plasma ghrelin levels in rats with lipopolysaccharide-induced wasting syndrome and effects of ghrelin treatment on the syndrome. Endocrinology. 144:5365-5371.

49. Murray, C.D., Kamm, M.A., Bloom, S.R., and Emmanuel, A.V. 2003. Ghrelin for the gastroenterologist: history and potential. Gastroenterology. 125:1492-1502

50. Dixit, V.D., Sridaran, R., Edmonsond, M.A., Taub, D., and Thompson, W.E. 2003. Gonadotropinreleasing hormone attenuates pregnancy-associated thymic involution and modulates the expression of antiproliferative gene product prohibitin. Endocrinology. 144:1496-1505.

51. Sherman-Baust, C.A., et al. 2003. Remodeling of the extracellular matrix through overexpression of collagen VI contributes to cisplatin resistance in ovarian cancer cells. Cancer Cell. 4:377-386. 